\title{
Inspections and Reports on Dwellings: Reporting for Sellers
}

\author{
Ian Melville and Ian Gordon \\ EG Books, London; 2008: ISBN 978-0-7282-045-8; 300pp; £39.99; paperback
}

Journal of Building Appraisal (2009) 4, 237-238. doi:10.1057/jba.2008.41

This book is the last of four volumes that form a series called Inspections and Reports on Buildings. The reviewer has not seen the other volumes and must therefore review this book on a stand-alone basis. On that pretext the reviewer confesses a degree of surprise at the apparent focus of this book as the Home Condition Report was dropped from being a requirement of the mandatory Home Information Pack. It would be the reviewer's opinion that the market for sellers to pay for such non-mandatory survey work would therefore be limited, and consequentially the market for owning this volume. However, there is still a mandatory requirement for energy assessments to be undertaken and the book additionally deals with such reports.

The book instantly strikes a sound chord with the reviewer as it differentiates between the surveyor who performs a survey and the potentially less qualified and experienced Home Inspector who purely inspects. The difference between the survey and the inspection is clearly stated as is the fact that the survey is undertaken for the benefit of the client while the inspection serves the terms of the procedure. There are clear instructions on writing survey reports which would be ideal for trainee surveyors, given the diversity of their backgrounds and the rapidity of their accreditation process also ideal for the practicing Home Inspector to follow.

The following chapter, while probably not intended to do so, serves to illustrate the gulf in quality between the accreditation process to become a Home Inspector and that required to become a Chartered Surveyor through the Royal Institution of Chartered Surveyor's APC process, or to become a surveyor through the Chartered Institute of Building's professional membership route. However, this book perhaps unwittingly continues to be invaluable to the non-Inspection-only focused trainee surveyor as it illustrates a professional requirement for surveyors to make quality, unambiguous notes and to keep them for possible production long after the report has been delivered.

The book proceeds on to the performance of the home inspection. It picks up anomalies between completing the Home Inspection Report and a professionally undertaken survey, in that the absence of visible defects on an internal wall does not preclude the likelihood of short-term maintenance issues resulting from age or construction form. However, the reviewer can see that such information for a Home Inspector who is limited by the HIR rulebook may prove confusing. The reviewer is consequentially still unsure at who this book is aimed at.

The reviewer personally found the next section of great interest. After personal experience of an energy inspection report that due to inadequacies of the computer system which could not accept data of $200 \mathrm{~mm}$ of insulation found within a flat roof structure which had been incorporated into a pitched roof and an inspector who lacked a basic understanding of building technology, the reviewer revelled as the authors bared the inadequacies, failures and outright stupidity of the current reporting procedure. The rationale for a system that works is also stated; however, the reviewer is becoming even 
less certain of the value of this book to the Home Inspector who wishes to ply their trade with confidence.

The book provides some excellent illustrations of best practice inspection reports; however, the reviewer suspects that any seller reading this book may not find that their fee results in reports which are so well constructed or written. One fact that struck the reviewer was the gap in technical quality between the Home Inspector's Report and the Scottish Single Survey Report. It might perhaps be worthwhile taking that crash course in Scottish architectural terminology.

In summary, this book is excellent as an entertaining and technical read for those interested in property surveying. It is part of a set of four books. This may prove an essential factor in its worth, because at a face value of $£ 40$ it seems to be as a stand-alone text to not specifically target any market, as it majors on reports that are no longer mandatory and would not be usually undertaken by the professionally qualified surveyor. It would seem in parts to undermine the confidence in their training of the home inspector, and would only appeal in parts to those studying to be surveyors.

Simon Mclean Managing Editor 